\title{
Bewusstes Erinnern und bewusstes Vergessen
}

\author{
Der juristische Umgang mit der Vergangenheit in den Ländern Mittel- und \\ Osteuropas \\ Hrsg. v. Angelika Nußberger u. Caroline von Gall
}

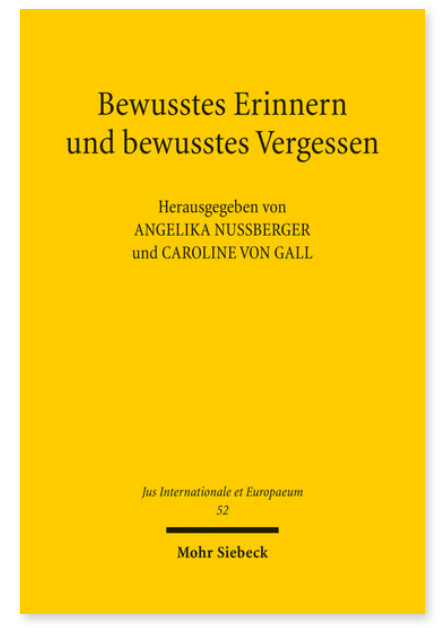

2011. XIV, 400 Seiten. JusIntEu 52

ISBN 978-3-16-151753-2

DOI 10.1628/978-3-16-151753-2

eBook PDF 104,00 €

ISBN 978-3-16-150862-2

fadengeheftete Broschur 104,00 €
Für die Länder Mittel- und Osteuropas war das 20. Jahrhundert mit einschneidenden Systemumbrüchen verbunden. Dies brachte die Herkulesaufgabe mit sich, die Rechtssysteme grundlegend umzugestalten und neue verbindliche Wertorientierungen vorzugeben. Vergangene Ungerechtigkeiten galt es auszugleichen ohne dabei rechtsstaatliche Postulate zu verletzen. Der Sammelband geht dem komplexen Ineinandergreifen von Recht und Geschichte im Rahmen dieses Transformationsprozesses aus unterschiedlichen Blickwinkeln nach. Diskutiert werden die Rolle des Strafrechts bei der Aufarbeitung von Systemunrecht, die Vergangenheitsbewältigung durch neu geschaffene Verfassungsgerichte, Konfliktvermeidungsstrategien bei der Neubestimmung von Staatsgrenzen sowie das Minderheiten- und Eigentumsrecht, aber auch jüngste Initiativen in Russland und der Ukraine, die Leugnung besonderer historischer Ereignisse gesetzlich zu verbieten.

\section{Inhaltsübersicht}

I) Der wertende Blick zurück - Geschichts- und Rechtswissenschaft im Vergleich

Martin Schulze Wessel: Geschichte vor Gericht. Zum juristischen und geschichtswissenschaftlichen Umgang mit dem Unrecht untergegangener Staatsordnungen in Deutschland und im östlichen Europa - Angelika Nußberger:

Vergangenheitsbewältigung und Recht - eine fortwirkende Herausforderung

II) Staatenbildung und Grenzziehung - die Fortwirkung der Geschichte

Otto Luchterhandt: Grenzen in Mittelasien und uti possidetis-Prinzip: Der Fall »Fergana-Tal - Tomasz Milej: Der uti possidetis-Grundsatz und seine Anwendung auf die Staatenzerfallsprozesse im ehemaligen Jugoslawien - Władysław Czaplińki: Die Grenzen Polens

III) Minderheitenrecht auf historischer Grundlage

Michael Geistlinger: Minderheiten im Kaukasus - Umsetzung von Mythen in Recht? - Carmen Schmidt: Historische Prägung des Minderheitenrechts in Russland - Vladimir Krjažkov: Die staatsrechtliche Stellung der indigenen Völker des Nordens im Kontext der historischen Entwicklung Russlands - Nina Waschkau: Russlanddeutsche in der russischen Gesetzgebung: Probleme und Lösungen - Herbert Küpper: Ungarische Minderheiten außerhalb der Grenzen Ungarns - die fortwirkende Bedeutung des Vertrags von Trianon

IV) Die Aufarbeitung der Geschichte als Thema der Verfassungsrechtsprechung und der Rechtsprechung des Europäischen Gerichtshofs für Menschenrechte

Pavel Holländer: Argumentation auf historischer Grundlage - das Beispiel des tschechischen Verfassungsgerichts - Gábor Halmai: Argumentation auf historischer Grundlage - das Beispiel des ungarischen Verfassungsgerichts - Anatolij Kononov: Argumentation auf historischer Grundlage - ein Beispiel des Verfassungsgerichts der Russländischen Föderation - Lech Garlicki: Eigentumsrechtliche Probleme in der Rechtsprechung des Europäischen Gerichtshofs für Menschenrechte (EGMR) V) Juristische Geschichtspolitik - Regelungen und Reglementierungen

Caroline von Gall: Gesetzliche Zementierung eines geschichtlichen Weltbildes in Russland - Die Gesetzentwürfe über die Haftung für die Verfälschung der Geschichte - Alfred Sproede: Vergangenheitsbewältigung und Erinnerungspolitik im postsowjetischen Raum: Das ukrainische Recht und die Hungerkatastrophe von 1932/33, der sog. Holodomor - Friedrich-Christian Schroeder: Der Einsatz des Strafrechts zur Durchsetzung historischer Gerechtigkeit - Andrej Umansky: Geschichtsschreiber wider Willen? Einblick in die Quellen der »Außerordentlichen Staatlichen Kommission « und der »Zentralen Stelle« - Alexander Trunk: Neues Recht und alte Sachverhalte - Bemerkungen zum intertemporalen Recht Russlands bei privatrechtlichen Sachverhalten - Tamara Morščakova: Was lehrt uns die Geschichte?

Caroline von Gall ist Juniorprofessorin am Institut für osteuropäisches Recht und Rechtsvergleichung der Universität zu Köln.

Angelika Nußberger ist ehemalige Richterin und ehemalige Vizepräsidentin am Europäischen Gerichtshof für Menschenrechte und Professorin für Verfassungsrecht, Völkerrecht und Rechtsvergleichung an der Universität zu Köln.

Jetzt bestellen:

https://mohrsiebeck.com/buch/bewusstes-erinnern-und-bewusstes-vergessen-9783161517532?no_cache=1 order@mohrsiebeck.com

Telefon: $+49(0) 7071-923-17$

Telefax: $+49(0) 7071-51104$ 